\title{
Circulating cell free DNA and miRNA Amount in Congenital Hearing Loss
}

\begin{abstract}
Ozge Caglar *, [MD]
Akin Cayir $^{2,3}$, [MD]

Begum Cilgin ${ }^{4}$, [MD]

F. Sefa Derekoy ${ }^{1}$, [MD]

1, Otorhinolaryngology-Head and Neck Department,

Medicine Faculty, Canakkale Onsekiz Mart University,

Turkey.

2, Vocational Health College, Canakkale Onsekiz Mart

University, Canakkale, Turkey.

3, Human Nutrition Research Centre, Institute of Cellular Medicine, Newcastle University, Newcastle upon Tyne, United Kingdom

\section{nee) ABSTRACT Com}

Objective: Our aim is to detect the amount of miRNA and free DNA in the peripheral blood of young people with congenital hearing loss and compare this with control group.

Materials and Methods: In our study, 16 patients who have congenital hearing loss and go to the private school for deaf children and 16 healthy individuals were selected in the same age group. $5 \mathrm{cc}$ blood was taken from peripheral vessels of each individual. We compared the circulating cell-free DNA and miRNA amount with the results of the control group.

Results: The ccfDNA amount of the patients with hearing loss was lower than the control group and It was statistically significant. On the contrary, we found the higher amount of ccfmiRNA in plasma samples of the patients with hearing loss. The statistical analysis showed that ccfmiRNA amount in congenital loss is consistently significantly higher than the control group.

Conclusion: The miRNA and freeDNA can be used early in the diagnosis of congenital hearing loss.
\end{abstract}

4, Medical Biology, Medicine Faculty, Canakkale Onsekiz Mart University, Turkey.

*Corresponding Author: Ozge Caglar

Otorhinolaryngology-Head and Neck Department, Medicine Faculty, Canakkale Onsekiz Mart University, Turkey

DOI: https://doi.org/10.32552/2018.ActaMedica.306

Email:ozgecaglar@comu.edu.tr

Received: 22 June 2018, Accepted: 18 September 2018,

Published online: 30 September 2018
Key Words: Congenital, hearing loss, miRNA, free DNA.

\section{INTRODUCTION}

Sensorineural hearing loss is the most common disease of the sensory system. It is estimated that 1-3 per 1000 births can lead to severe hearing loss. Approximately $50 \%$ of prelingual hearing loss cases have a genetic background [1]. The etiology of hearing loss in children is almost equal to genetic and environmental factors [2]. Percent of them are specified as nonsendromal [3].

Mutation in the GJB2 (gap junction beta-2 protein) gene is the most common cause of genetic deafness [4]. The GJB2 gene encodes connexin 26 (CX26), a transmembrane protein that functions in the inner ear to regenerate potassium through the formation of gap junctions [5]. The connexins are located in the cell junctions of the epithelial cells and in the connective tissue of the cochlear nucleus and are responsible for maintaining an electric potential in the cochlea.

A mutation in the SLC26A4 gene leads to Pendred Syndrome (PS), which is the second most prevalent mutation and occurs with enlarged vestibular aquaduct syndrome (EVAS) [6].

SLC26A4 is an anion (chloride / iodide / bicarbonate) carrier coding for the kidneys, inner ear and thyroid, 
called pendrin. SLC26A4 mutations are responsible for about $5-7 \%$ of genetic deafness cases.

MT-RNR1 mutations encoding mitochondrial 12S ribosomal RNA (12s rRNA) may increase susceptibility to aminoglycoside toxicity and have no maternal effect. MtDNA1494C> G mutation is common in $0.45 \%$ of hearing-impaired children [7].

The most common nongenetic cause of SNHL is seen in congenital cytomegalovirus (CMV) infection. Nance et al. [4] reported that CMV infections constituted approximately $21 \%$ of congenital SNHL cases and $25 \%$ of SNHL cases.

A comprehensive diagnostic method for the patient with sensorineural hearing loss (SNHL) is vital to guide treatment and intervention options. Central Nervous System Magnetic Resonance Imaging (MRI) provides a useful tool for the identification of intracranial and inner ear abnormalities in addition to laboratory studies to detect inherited and contagious causes of SNHL [5].

Abnormal levels of free DNA in serum and plasma in cancer patients were first shown in 1977 [8]. However, the use of prognosis and diagnosis as a marker has recently been discussed. In a cancer group, for example, colorectal, pancreas, lung, bladder, bass-neck, liver, free DNA mutations were detected [9-12].

CcfDNA circulation can be found in healthy individuals and in patients with non-malignant diseases, including systemic lupus erythematosus, rheumatoid arthritis, pulmonary embolism or myocardial infarction [13-15]. In addition, trauma [16] and therapeutic procedures [17] can also lead to the release of free DNA into the circulation

Although the source of CcfDNA is not clear, there are various mechanisms that contribute to the amount of DNA in circulation. Mechanisms that contribute to the CcfDNA may vary depending on the type of disease and its condition. It is accepted that dead or dying cells are the main source of ccfDNA. However, it has also been proven that live cells can release the ccfDNA. Also, the amount in circulation may vary depending on the disease stage [18].

MicroRNAs (miRNAs) are small, endogenously uncoded RNA molecules [19]. It acts as a negative regulator in gene expression. These molecules are critical post-transcription regulators of gene expression. For this reason, it is not surprising that miRNAs have been tightly regulated in a manner that allows them to be appropriately shaped in a temporarily restricted and tissue-specific manner for structured organism development and growth [20]. Studies have shown that miRNA plays an important role in cellular functions, such as proliferation, apoptosis, metastasis, and cellular changes [21-22].
In this research, we planned to look at these two molecules, which can be detected in plasma, in patients with congenital hearing loss.

\section{MATERIALS AND METHODS}

\section{Participants}

In the present study, we included 16 individuals who has congenital hearing loss. All are students in the private school for deaf children and all have medical record regarding their hearing loss. Before taking peripheral blood samples, the patients and controls were informed about the study and its aims and then each gave their consent by signing the appropriate form. The characteristics of the patients and the controls were collected by means of a questionnaire. Ethical permission was granted by the Faculty of Medicine Ethics Committee.

\section{Collecting and storage samples}

For the ccfDNA and ccfmiRNA, $5 \mathrm{~mL}$ blood was collected in sterilized tubes containing K3-EDTA containing tube. After taking, the blood samples were immediately centrifuged at $3000 \mathrm{~g}$ for $10 \mathrm{~min}$. The plasma samples were transferred to another sterile, DNAse free tube (RNAser free tube for miRNA) and the samples were centrifuged at $16000 \mathrm{~g}$ for 10 min. Then, the plasma samples were separated and stored at $-80^{\circ} \mathrm{C}$ for further study. The DNA content of the plasma samples was measured directly with a fluorescence-based Quant-iT ${ }^{\mathrm{TM}}$ high-sensitivity DNA assay kit and a Qubit ${ }^{\circledast}$ fluorometer (Invitrogen, Carlsbad, CA, USA). The Qubit $^{\circledR} 2.0$ Fluorometer is used for quantitation of DNA, RNA, and protein. It uses specific dyes for each type of molecule which have extremely low fluorescence until they bind to their targets. After binding, they give off an intensely fluorescent signal which is directly proportional to the DNA concentration of any solution. In the present study, the ccfDNA amount of each individual was measured using a DNA curve obtained from the DNA standard of known concentrations. Plasma samples were analyzed in duplicate and the mean of the two values was used as the final DNA amount. The between-measurements and coefficients of variation of this assay were less than $1.00 \%$.

\section{Statistical analysis}

We used Man Whitney $U$ test. 


\section{RESULTS}

All the congenital loss patients are male. Their age range was 15-21 and the mean age of the population was 18.11 and the median was 18.0. Except one, other did not smoke and had no any alcohol habit. In addition to hearing loss, they had no any additional diseases. Five participants have also hearing loss from their family member who were their first relatives. Among 17 participants, the parents of the 11 participants were farmer. We included 17 healthy individuals as the control. All the control are again male. The mean age of the control is 19.1, and the median is 19 . In the control only 5 of the 16 was smokers. Additionally, 14 out of the control had alcohol habit. The controls have no additional diseases. When the patients' BERA tests were examined, it was seen that the hearing averages of the patients were $(85-100 \mathrm{~Hz}) 90 \mathrm{~Hz}$ (Table 1). Because the hearing loss could not be diagnose in the early time, they can only contact with the sign language with other people.

No statistically significant difference was found between patients and control group's age and gender.

Table 1. Patient and control group characteristics

\begin{tabular}{|l|c|c|}
\hline & Patients & Control \\
\hline Gender & 17 (male) & 17 (male) \\
\hline Age & $15-21(18.1)$ & 5 \\
\hline Smoking & 1 & - \\
\hline BERA & $90 \mathrm{~Hz}(19.1)$ \\
\hline Farming (family) & 11 & - \\
\hline Siblings (hearing loss) & 5 & - \\
\hline
\end{tabular}

The ccfDNA amount of the congenital loss was 1.43 times lower than the control. The Mann-Whitney $\mathrm{U}$ test showed that the amount is significantly higher than the control $(P<0.0001)$. On the contrary, we found the higher amount of ccfmiRNA in plasma samples of congenital loss patients. The statistical analysis showed that ccfmiRNA amount in congenital loss is consistently significantly higher than the control $(P<0.0001)$. We investigated the any relationship using Spearman's rho correlation. We found that there is a negative correlation between ccfD$N A$ and ccfmiRNA ( $r=-0.56, P=0.001)$. We investigated that the three are significant correlation between age and ccfDNA ( $r=0.48, P=0.005)$, and age and ccfmiRNA ( $r=0.67, \mathrm{P}=0.0001$ ) (Table 2 ).

Table 2. ccfDNA and ccfmiRNA amount in different groups

\begin{tabular}{|l|c|c|c|c|}
\hline \multirow{2}{*}{} & Control & Hearing Loss & Control & Hearing Loss \\
\cline { 2 - 5 } & ccfDNA & ccfDNA & ccfmiRNA & ccfmiRNA \\
\hline Total Mean & $604.58 \pm 87.00$ & $423.18 \pm 78.05$ & $1532.47 \pm 318$ & $2543.52 \pm 235.6$ \\
\hline Minimum & 390 & 286 & 882 & 2200 \\
\hline Maximum & 732 & 580 & 2120 & 3080 \\
\hline
\end{tabular}

\section{DISCUSSION}

Congenital hearing loss caused by genetic reasons is highly heterogeneous. More than 150 loci responsible for this type of hearing loss and more than 100 genes are known. Genetic condition prelingual deafness is usually associated with a mutation in the connexin 26 gene. The majority of such hearing loss cases are detected during screening tests in newborns; However, there are rare cases of rare or progressive sensorineural hearing loss [23].

Norris et al. [24] reported a case in which a mutation in the GJB2 gene was deferred in neonates with normal hearing results that were detected in the future.

The European Network of Molecular Genetics maintains diagnostic tests for genetically-induced hearing loss [25]. However, this report does not suggest tests for single point mutations such as $35 \mathrm{delG}$. The authors suggest that screening tests of the most common genetic abnormalities should be performed and, if there are adverse consequences, the sequence of exon 2, the analysis of the 5 'and 3' ends of intron 1, and the deletion of GJB6 deletions. 
In addition, if at least one point mutation is detected in the GJB2 gene, it is advisable to detect deletions in GJB6.

Burke et al. and Kim et al. a heterozygote ratio increases with normal hearing in a group with sensory hearing loss compared to the control group $[26,27]$. In rats, reduced expression of connexin 26 after 18 days of birth has increased the susceptibility of Corti's normal organ to acoustic trauma and degenerative lesions [28]. Van Eyken and his friends work. In humans, GJB2 mutations have been associated with lack of correlation with increased susceptibility to acoustic trauma or aging in the hearing system [29]. However, A1555G mutations in the mitochondrial subunit of the 12s rRNA have shown increased susceptibility to ototoxic injury caused by aminoglycosides [6].

When we took a look at literature, mit DNA mutation has been found to be high in children with congenital hearing loss [30-31], but we didn't find any research about miRNA, free DNA and hearing loss, therefore, our research is important.

As it is seen in literature, the most important reason of congenital hearing loss is genetic. When we were researching, we found that 5 patients had siblings that have hearing loss and they were diagnosed very late. The above-mentioned genetic studies may not be give conclusion in a short time, accurate results may not be obtained in hearing screenings (OAE, ABR). Therefore, new methods are needed which can be done easily and diagnosed. This is the greatest aim of this research;

Approximately $65 \%$ of patients's family are interested in farming, and no research has been found in the literature. It is also thought that this issue is to be emphasized and to be studied extensively.

Organ development requires well established non-cellular communication to coordinate cell proliferation and differentiation. MicroRNAs (miRNAs) are small, non-coding RNAs that regulate gene expression to a large extent and play a critical role in organ development. In a study in the literature, they found that miRNAs could pass through gap junctions between the natural cochlear support cells to play a role in cochlear development [32]. Connexin26 (Cx26) and Cx30 are dominant isoforms. Cx26 deficiency, Cx30 deficiency, cochlear developmental disorders. This data suggests that Cx26 mediated extracellular communication is required for cochlear development, and Cx26 deficiency may disrupt miRNA mediated intracellular genetic communication in the cochlea, which may lead to cochlear developmental disorders and congenital deafness, as previously reported.

In one research, venous blood, amniotic fluid, or chorionic villus of proband and couples were analyzed and free DNAs in maternal plasma were examined to determine whether they carry GJB2 235delC mutations, therefore; It may be a potential way to screen for congenital deafness based on maternal free DNA [33].

As we have seen in our study, ccFDNA and miRNA were obtained by simple blood collection technique, and miRNA was found to be higher in the patient group and CCFDNA was less, and statistical significiant was found. This research shows us that these molecules can be used for early diagnosis in patients with congenital hearing loss. The limitation in work is the small number of young people who are trained in a particular school because the group of our patients has hearing loss. But even though we have fewer patients, it is also important that we find meaningful differences.

\section{CONCLUSION}

The miRNA and freeDNA, which can be detected by blood from the peripheral vessel, can be used early in the diagnosis of congenital hearing loss.

\section{CONFLICT of INTEREST STATEMENT}

There is no conflict of interest among authors. 
[1] [1] Mielczarek M, Zakrzewska A, Olszewski J. GJB2 sequencing in deaf and profound sensorineural hearing loss children. Otolaryngol Pol 2016; 70 (3): 21-25.

[2] Kochhar A, Hildebrand MS, Smith RJ. Clinical aspects of hereditary hearing loss. Genet Med 2007; 9(7): 393- 408.

[3] Putcha GV, Bejjani BA, Bableoo $S$, et al. A multicenter study of the frequency and distribution of GJB2 and GJB6 mutations in a large North American cohort. Genet Med 2007; 9(7) 413- 426.

[4] Nance WE, Lim BG, Dodson KM. Importance of congenital cytomegalovirus infections as a cause for pre-lingual hearing loss. J Clin Virol 2006; 35(2): 221- 225.

[5] McClay JE, Booth TN, Parry DA, et al. Evaluation of pediatric sensorineural hearing loss with magnetic resonance imaging. Arch Otolaryngol Head Neck Surg 2008; 134(9): 945-952.

[6] Prezant TR, Agapian JV, Bohlman MC, et al. Mitochondrial ribosomal RNA mutation associated with both antibiotic-induced and non-syndromic deafness. Nat Genet 1993; 4(3): 289- 294.

[7] Kimani JW, Buchman Ca, Booker JK, et al. Sensorineural Hearing Loss in a Pediatric PopulationAssociation of Congenital Cytomegalovirus Infection With Intracranial Abnormalities. Arch Otolaryngol Head Neck Surg. 2010; 136(10): 999-1004.

[8] Leon SA, Shapiro B, Sklaroff DM, et al. Free DNA in the serum of cancer patients and the effect of therapy. Cancer Res. 1977 37(3): 646-650.

[9] Kirk GD, Lesi OA, Mendy M, et al. 249(ser) TP53 mutation in plasma DNA, hepatitis $B$ viral infection, and risk of hepatocellular carcinoma, Oncogene 2005; 24(38): 5858-5867.

[10] Mulcahy HE, Lyautey J, Lederrey C, et al. A pro- spective study of K-ras mutations in the plasma of pancreatic cancer patients, Clin. Cancer Res. 1998; 4(2): 271-275.

[11] Salbe C, Trevisiol C, Ferruzzi E, et al. Molecular detection of codon 12 K-RAS mutations in circulating DNA from serum of colorectal cancer patients, Int. J. Biol. Markers 2000; 15(4): 300-307.

[12] Utting M, Werner W, Dahse R, et al. Microsatellite analysis of free tumor DNA in urine, serum, and plasma of patients: a minimally invasive method for the detection of bladder cancer, Clin. Cancer Res. 2002; 8(1): 35-40.

[13] Galeazzi M, Morozzi G, Piccini M, et al. Dosage and characterization of circulating DNA: present usage and possible applications in systemic autoimmune disorders. Autoimmun Rev 2003; 2(1): 50-5.

[14] Steinman CR. Circulating DNA in systemic lupus erythematosus: Isolation and characterization. J Clin Invest 1984; 73(3): 832-41.

[15] Steinman CR. Circulating DNA in polyarteritis nodosa and related syndromes. Arthritis Rheum 1982; 25(12): 1425-30.

[16] Laktionov PP, Tamkovich SN, Rykova EY, et al. Extracellular circulating nucleic acids in human plasma in health and disease. Nucleosides Nucleotides Nucleic Acids 2004; 23(6-7): $879-83$.

[17] Davis GL, Davis JS. Detection of circulating DNA by counterimmu- noelectrophoresis (CIE). Arthritis Rheum 1973; 16(1): $52-8$.
[18] Schwarzenbach $\mathrm{H}$, Hoon DS, Pantel K. Cell-free nucleic acids as biomarkers in cancer patients. Nature Reviews Cancer 2011; 11(6): 426-37.

[19] Bartel DP. MicroRNAs: genomics, biogenesis, mechanism, and function. Cell 2004; 116(2): 281-297.

[20] Yates LA, Norbury CJ, Gilbert RJ. The long and short of microRNA. Cell 2013; 153(3): 516-519.

[21] Salajegheh A, Vosgha $H$, Rahman AM et al. Modulatory role of miR-205 in angiogenesis and progression of thyroid cancer. Journal of molecular endocrinology 2015; 55(3): 183-196.

[22] Santos MCT, Tegge AN, Correa BR et al. miR-124,-128, and -137 Orchestrate Neural Differentiation by Acting on Overlapping Gene Sets Containing a Highly Connected Transcription Factor Network. Stem Cells 2016; 34(1): 220-232.

[23] Pagarkar W, Bitner-Glindzicz M, Knight J, et al. Late postnatal onset of hearing loss due to GJB2 mutations. Int. J. Pediatr. Otorhinolaryngol. 2006; 70 (6): 1119-1124.

[24] Norris VW, Arnos KS, Hanks WD, et al. Does universal newborn hearing screening identify all children with GJB2 (Connexin 26) deafness? Penetrance of GJB2 deafness. Ear Hear. 2006; 27 (6): 732-741.

[25] Hoefsloot LH, Roux AF, Bitner-Glindzicz M. EMQN DFNB1 best practice meeting. EMQN Best Practice guidelines for diagnostic testing of mutations causing non-syndromic hearing impairment at the DFNB1 locus. Eur J Hum Genet 2013; 21(11): 1325-1329.

[26] Burke WF, Warnecke A, Schöner-Heinisch A, et al. Prevalence and audiological profiles of GJB2 mutations in a large collective of hearing impaired patients. Hear Res. 2016; 333: 77-86.

[27] Kim SY, Kim AR, Kim NK, et al. Unraveling of Enigmatic Hearing-Impaired GJB2 Single Heterozygotes by Massive Parallel Sequencing: DFNB1 or Not? Medicine (Baltimore) 2016; 95(14): e3029.

[28] Zhou XX, Chen S, Xie L, et al. Reduced Connexin26 in the Mature Cochlea Increases Susceptibility to Noise-Induced Hearing Loss in Mice. Int J Mol Sci 2016; 17(3): 301.

[29] Van Eyken E, Van Laer L, Fransen E, et al. The contribution of GJB2 (Connexin 26) 35delG to age-related hearing impairment and noise-induced hearing loss. Otol Neurotol 2007; 28(7): 970-975.

[30] Matsushima K, Nakano A. Arimoto Y, et al. High-level heteroplasmy for the m.7445A $>\mathrm{G}$ mitochondrial DNA mutation can cause progressive sensorineural hearing loss in infancy. Int J Pediatr Otorhinolaryngol. 2018; 108: 125-131.

[31] Mutai $\mathrm{H}$, Watabe T, Kosaki K. et al. Mitochondrial mutations in maternally inherited hearing loss. BMC Med Genet. 2017; 18: 32.

[32] Zhu Y, Zong L, Mei L, et al. Connexin26 gap junction mediates miRNA intercellular genetic communication in the cochlea and is required for inner ear development. Scientific Reports 5, 2015; Article number:15647. DOi: 10.1038/srep15647

[33] Meng M, Huo R, Han MY, et al. Detection of common deafness mutation by maternal plasma cell-free DNA. European Review for Medical and Pharmacological Sciences 2014; 18(10): 1544-48. 